\title{
Building Quantitative Gene Regulatory Mechanism in Quorum Sensing in Pseudomonas aeruginosa Using Transcriptomic Data
}

\author{
Shaomin Yan 10 , Guang Wu (1)
}

State Key Laboratory of Non-Food Biomass and Enzyme Technology, National Engineering Research Center for Non-Food Biorefinery, Guangxi Key Laboratory of Biorefinery, Guangxi Academy of Sciences, Nanning, China

Correspondence to: Guang Wu, hongguanglishibahao@gxas.cn

Keywords: Gene Quantitative Regulatory Mechanism, Pseudomonas aeruginosa, Quorum Sensing,

Transcriptomic Analysis

Received: January 25, $2020 \quad$ Accepted: February 25, $2020 \quad$ Published: February 28, 2020

Copyright $\odot 2020$ by author(s) and Scientific Research Publishing Inc.

This work is licensed under the Creative Commons Attribution International License (CC BY 4.0).

http://creativecommons.org/licenses/by/4.0/

\section{(c) (i) Open Access}

\section{ABSTRACT}

A large amount of transcriptomic data provides opportunities 1) to verify the gene regulatory mechanism, which is usually obtained from a single experiment, at population level; 2) to uncover the gene regulatory mechanism at population level; and 3) to build a quantitatively gene regulatory mechanism. One of the best studied regulatory mechanisms in bacteria is the quorum sensing (QS), which plays an important role in regulation of bacteria population behaviors such as antibiotic production, biofilm formation, bioluminescence, competence, conjugation, motility and sporulation. Pseudomonas aeruginosa is a Gramnegative bacterium causing diseases in plants, animals, humans, and its biofilm and drug-resistance become great concerns in clinics. $P$. aeruginosa has three QS systems including a specific one for Pseudomonas. In this study, the transcriptomic data of $P$. aeruginosa were combined from 104 publications and QS gene expressions were analyzed under different experimental conditions. The results demonstrate the quantitatively regulatory mechanisms of QS genes at population level including 1) to rank and group QS-related genes according to their activity; 2) to quantitatively define the role of a single global regulator; 3 ) to find out the probability that a global regulator impacts QS genes and the probability that a QS gene responds to global regulators; and 4) to search for overlapped genes under four types of experimental conditions. These results provide integrative information on understanding the regulation of QS genes at population level. 


\section{INTRODUCTION}

From big data to knowledge is the landmark for big data era [1] because the exponential growth of data provides an opportunity to use big data to generate new knowledge. For gene regulatory mechanisms, the large amount of transcriptomic data provides opportunities 1) to verify the gene regulatory mechanism, which is usually obtained from a single experiment, at population level ;2) to uncover the gene regulatory mechanism at population level; and 3 ) to build a quantitatively gene regulatory mechanism.

Quorum sensing (QS) in bacteria is a cell-to-cell communication through production and detection of autoinducers, and response to autoinducers. Thus, a bacterium can coordinate its own behavior with a population behavior upon the concentration of autoinducers, which is subject to cell density [2]. At genetic level, QS regulatory mechanism has been well studied over years, i.e. bacteria regulate their gene expression according to their population size [2]. This regulation results in antibiotic production, biofilm formation, bioluminescence, competence, conjugation, motility and sporulation.

For bacteria, QS is generally composed of two components: 1) an autoinducer synthase, which is a member of LuxI family (accession no. pfam00765) and produces an $\mathrm{N}$-acylhomoserine lactone (AHL); and 2) a transcriptional regulator, which is a member of LuxR family (accession no. pfam03472) and activates or represses the transcription of targeted genes after binding of AHL [3-5].

Pseudomonas aeruginosa is a Gram-negative bacterium causing diseases in plants [6], animals [7], and humans, where the cystic fibrosis is a major concern [8-10]. P. aeruginosa has three QS systems. The first is LasI-LasR, which is related to synthesis and use of N-(3-oxo-dodecanoyl)-L-homoserine lactone $\left(3 \mathrm{OC}_{12}-\mathrm{HSL}\right)$ [8]. The second is RhlI-RhlR, which is related to synthesis and use of $\mathrm{N}$-(butanoyl)L-homoserine lactone $\left(\mathrm{C}_{4}\right.$-HSL) [11]. These two QS systems essentially are $\mathrm{N}$-acylated homoserine lactone (AHL)-based QS systems [12] in many bacteria. The third is the Pseudomonas quinolone signal (PQS)-based system, PqsABCDH-PqsR, which is related to synthesis and use of 2-heptyl-3-hydroxy4-quinolone (HHQ) [13, 14].

For these three QS systems, their gene regulatory mechanism is the objective of many studies and reviews [15-17]. Basically, this regulatory mechanism indicates that QS system is a positive feedback system at QS level, i.e. a close loop exists for each pair, LasI-LasR through 3OC12-HSL, RhlI-RhlR through C4-HSL, and PqsABCDH-PqsR through HHQ.

The regulatory mechanism among three QS systems in $P$. aeruginosa includes both positive and negative feedbacks: 1) LasR regulates both RhlR and PQS positively through the complex 3OC12-HSL-LasR $[12,18-20]$; and 2) PQS positively regulates rhlI expression [21]. The only negative regulation among QS systems is that RhlR negatively regulates PqsR in $P$. aeruginosa $[12,22]$. But this negative feedback seems not to be sufficient to stop QS because QS response is not reversed for small decreases in population density in $P$. aeruginosa [16].

Usually, QS-controlled genes are not active unless the population density reaches the threshold [23 ]. Therefore there is a regulatory mechanism that preventing QS genes from expression at "prequorum" period $[23,24]$. The genes controlling QS genes are termed differently such as super-regulators of QS [17], QS regulators [23], global regulators [25-27].

Negative global regulators for both LasI-LasR and RhlI-RhlR systems are 1) QteE inhibits QS system by reducing LasR protein stability and reducing RhlR levels [23]; 2) MvaT (PA4315) works as a repressor for QS [25]; 3) AlgR2 (AlgQ, PA5255) negatively modulates lasR and rhlR [28]; and 4) RpoN ( 654 , PA4462) inhibits lasR and lasI genes at a low cell density [26] and inhibits rhlR and rhlI genes throughout growth because a potential RpoN recognition sequence exists in the rhlI promoter [26, 29].

Negative global regulators for LasI-LasR system include 1) QscR (PA1898) represses LasI [18, 30]; 2) QslA (PA1244) inhibits LasR by preventing its binding to DNA [31, 32]; and 3) RsaL (PA1431) inhibits lasI by binding to rsaL-lasI promoters [33, 34], then negatively feedbacks itself [35], and controls over 130 genes [36]; and 4) RsmA (PA0905) inhibits lasI [37].

Negative global regulators for RhlI-RhlR system are 1) DksA (PA4723) inhibits rhlI and further inhibits both $\operatorname{rhl} A B$ (rhamnosyltransferase for virulence factor rhamnolipid) and lasB (elastase) [38-40] be- 
cause the expression of lasB needs the complex C4-HSL-RhlR [41]; 2) Lon (PA1803) negatively regulates RhlR/RhlI by degrading LasI [42]; 3) RpoS (PA3622) inhibits $r h l I ~[18,43-45]$, although an opposite result was observed [18].

The negative global regulator for PQS system is QslA (PA1244), which negatively regulates PqsR protein [31].

Positive global regulators for LasI-LasR system include 1) GacA (PA2586)/GacS (PA0928) promoting lasR in $P$. aeruginosa [46, 47] and $P$. putida [48]; 2) Vfr (PA0652) promoting lasR in $P$. aeruginosa through the cyclic AMP receptor protein-binding and rhIR [49]; 3) VqsR (PA2591) promoting lasI [27].

Additionally, VqsM (PA2227) is sometimes positioned beyond global regulators because it positively regulates VqsR (PA2591), RpoS (PA3622) and PprB (PA4296) [50].

Collectively, there are eleven negative global regulators (AlgR2, DksA, Lon, MvaT, QscR, QslA, QteE, RpoN, RpoS, RsaL and RsmA), and four positive global regulators (GacA, GacS, Vfr and VqsR). Moreover, there is interaction among global regulators, for example, VqsR (PA2591) directly inhibits QscR (PA1898) through binding to $q s c R$ promoter region [51].

In the 1990s, transcription of aprA (PA1249), las A (PA1871) and toxA (PA1148) was found to require LasR [52]. Since then, the number of genes under QS control in $P$. aeruginosa varies from experiment to experiment, ranging from $1 \%-4 \%$ genes [43], to $10 \%$ genes [15, 16], and to $11 \%$ genes [53]. Recently, the number of QS-controlled genes by las and rhl systems reached 616 genes [53].

Also, two AHL-acylases, PvdQ (PA2385) and QuiP (PA1032), play a role in controlling AHL homeostasis by adjusting its level $[54,55]$. Still, the import-export pumps, i.e. mexE (PA2493), mexF (PA2494), $\operatorname{oprN}$ (PA2495) [56], mexG (PA4205), mexH (PA4206), mexI (PA4207) and opmD (PA4208) [57] are important for QS. Moreover, pfm (PA2950), enoyl-CoA reductase, has its influence on QS [58].

At this point, the QS regulatory mechanism is clear, but its quantification is needed because each individual gene responds differently. For example, some genes well respond to las $A$, some genes respond well to $\operatorname{rhl} A B$, and some genes equally respond to both $[15,59]$. Moreover, QS regulatory mechanism was usually obtained from an individual experiment. However, the performance of each component at population level has yet to fully understand.

A way to deal with the abovementioned issues is to assemble and analyze the transcriptomic data together because they dynamically and globally record the gene response to various experimental conditions. In this study, the transcriptomic data from 104 journal publications on $P$. aeruginosa were combined and QS gene expressions under different conditions were analyzed in order at population level 1) to rank QS genes according to their activity, 2) to verify the regular pathways, and 3) to uncover QS regulatory mechanism, and 4) to build a quantitative gene regulatory mechanism.

\section{MATERIALS AND METHODS}

Affymetrix $P$. aeruginosa array is widely used in transcriptomic studies. Platform GPL84 is specially designed for $P$. aeruginosa PAO1 and contains 5549 P. aeruginosa genes. Gene Expression Omnibus (GEO) requires archiving all the transcriptomic data [60, 61]. The GPL84 datasets from 104 journal publications (Supplementary Info) were analyzed for this study. Yet, these 104 studies were all the studies we could find at the beginning of our study.

Basically, these data come from different experiments with different measurement standards and cut-off values. Therefore, we reformatted them according to the measurement standard of signal intensity with cut-off value of 2, which is the statistical significance used in these studies (Supplementary Datasets 1 and 2).

For an individual transcriptomic study, the focuses are usually placed on how many genes are up/ down-regulated and which gene is up/down-regulated under experimental conditions. As a result, we can estimate a gene's activity at population level through counting its up/down-regulated frequency in all available transcriptomic studies. Indeed, this activity represents a gene's function under all the experimental conditions, so it is an activity at population level. In this manner, we have the activity of all up-regulated and down-regulated QS-related genes at population level (Figure 1 and Figure 2, and Supplementary 


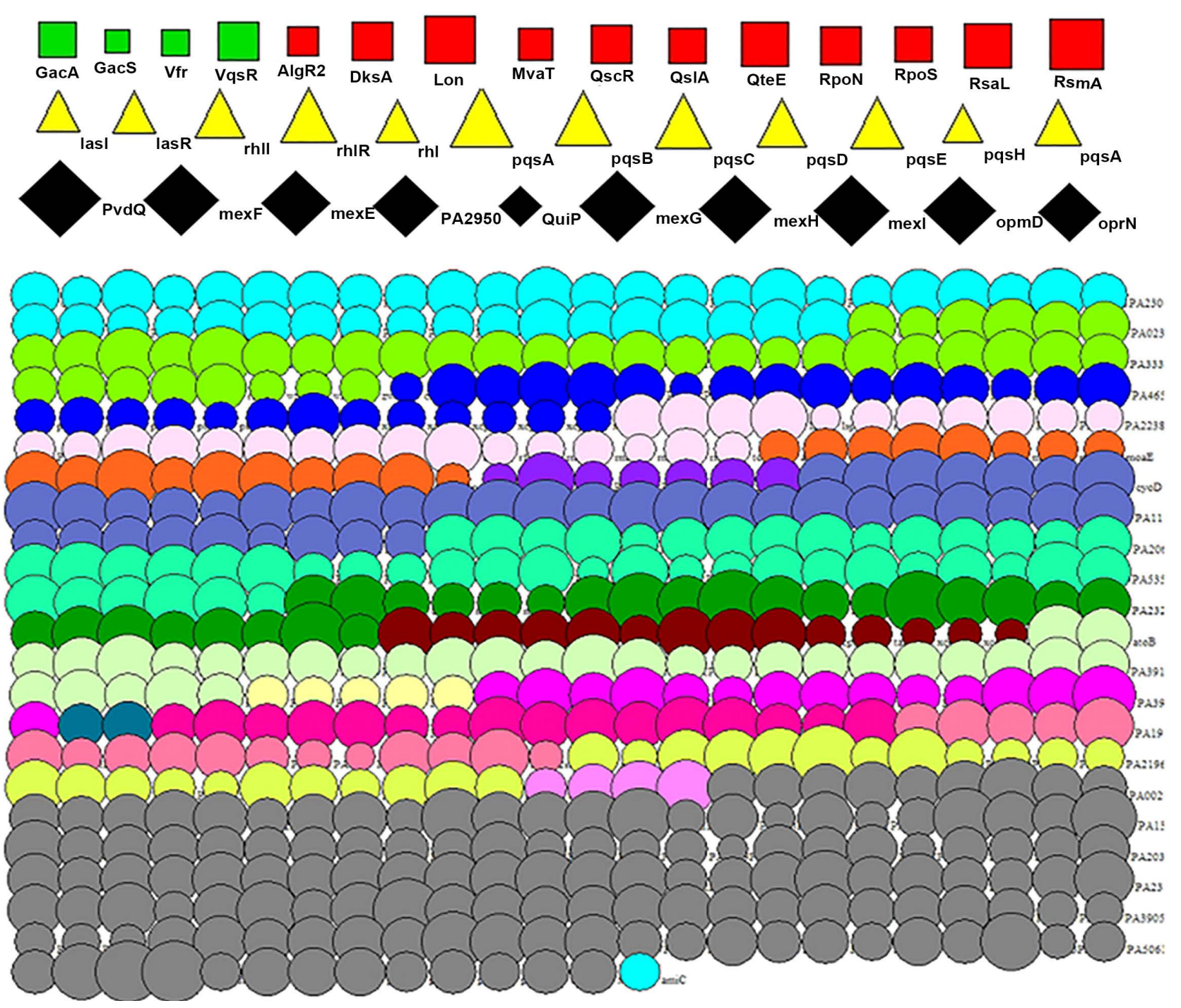

Figure 1. Quantitative activity of QS-related genes under up-regulation. Each symbol represents a gene and its size is proportional to its up-regulation frequency at population level. From the top row down, 1) green and red squares are positive and negative global regulators, 2) yellow triangles are QS genes, 3) black diamonds are the genes affecting AHL levels, and 4) circles are QS-controlled genes, whose encoding proteins are colored according to Pseudomonas classification [63,64] as follows: 1) cyan-amino acid transport and metabolism; 2) lime green-carbohydrate transport and metabolism; 3) blue-cell motility; 4) pink-cell wall/membrane/envelope biogenesis; 5) orange-coenzyme transport and metabolism; 6) purple-defense mechanisms; 7) cadet blue-energy production and conversion; 8) teal blue-general function prediction only; 9) olive green-inorganic ion transport and metabolism; 10) maroon-intracellular trafficking, secretion and vesicular transport; 11) light green-lipid transport and metabolism; 12) light yellow-nucleotide transport and metabolism; 13) magenta-posttranslational modification, protein turnover and chaperones; 14) midnight bluereplication, recombination and repair; 15) wild strawberry-secondary metabolites biosynthesis, transport and catabolism; 16) salmon-signal transduction mechanisms; 17) green yellow- transcription; 18) lavender-translation, ribosomal structure and biogenesis; and 19) gray-function unknown or unclassified. For data details, see Supplementary Data Fig-1-2.xlsx. 


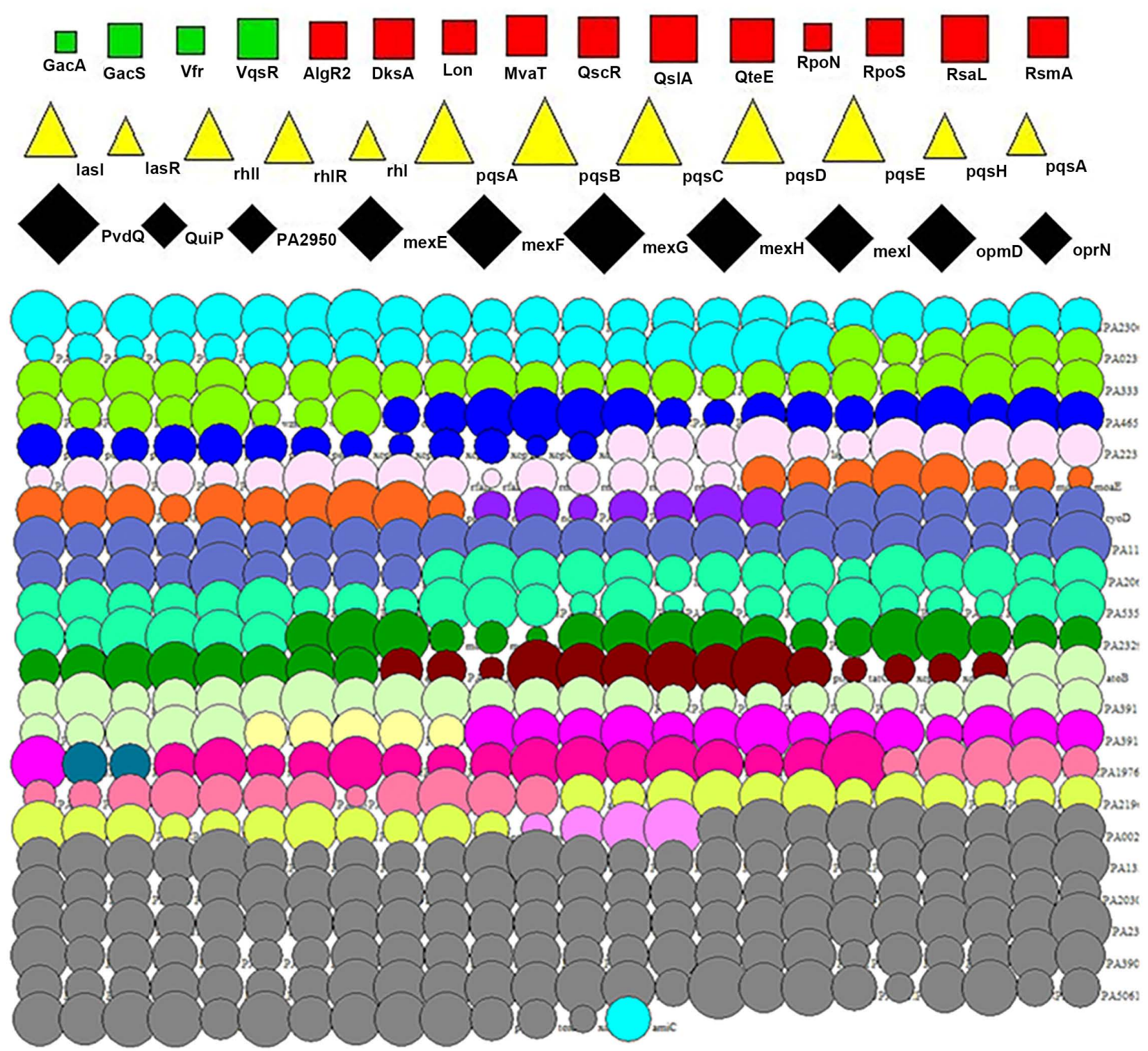

Figure 2. Quantitative activity of QS-related genes under down-regulation at population level (for the information on symbols and colors, refer to legend of Figure 1).

Data Fig-1-2). Subsequently, we can rank QS-related genes according to their activity at population level, and group QS-related genes (Tables 1-3).

Because QS regulatory pathways are usually intertwined together, it is hard to quantitatively define the role of a single global regulator. Therefore, the four scenarios were examined according to QS regulatory hierarchy: 1) which QS gene positively reacted to the up-regulation of a single global regulator with the rest global regulators unchanged (red number in Figure 3); 2) which QS gene negatively reacted to the up-regulation of a single global regulator with the rest global regulators unchanged (blue number in Figure 3); 3) which QS gene positively reacted to the down-regulation of a single global regulator with the rest global regulators unchanged (red number in Figure 4); and 4) which QS gene negatively reacted to the down-regulation of a single global regulator with the rest global regulators unchanged (blue number in Figure 4). These analyses can be done through looking at the abovementioned four scenarios in each transcriptomic dataset, and then summing them up. In this way, the relationship between a global regulator and each individual QS gene was established. 
Table 1. Grouping of global regulators in up/down-regulations according to their activity.

\begin{tabular}{ccccc}
\hline \multicolumn{2}{c}{ Global Regulators } & Up-Regulations & Down-Regulations & Group \\
\hline & AlgR2 & 8 & 12 & III \\
DksA & 14 & 13 & I \\
& Lon & 20 & 9 & II \\
MvaT & 10 & 13 & III \\
QscR & 14 & 14 & I \\
& QslA & 12 & 17 & III \\
& QteE & 17 & 15 & I \\
& RpoN & 13 & 6 & III \\
& RpoS & 11 & 12 & I \\
& RsaL & 17 & 18 & I \\
& RsmA & 24 & 13 & II \\
\hline Positive Regulators & GacA & 11 & 4 & II \\
& GacS & 5 & 9 & III \\
& Vfr & 7 & 6 & I \\
& VqsR & 14 & 14 & I \\
\hline
\end{tabular}

Table 2. Grouping of up/down-regulations of QS genes according to their activity.

\begin{tabular}{cccc}
\hline QS Genes & Up-Regulations & Down-Regulations & Group \\
\hline lasI & 12 & 19 & III \\
lasR & 12 & 9 & II \\
$r h l I$ & 16 & 17 & I \\
$r h I R$ & 21 & 16 & II \\
$r h l$ & 12 & 9 & II \\
$p q s A$ & 25 & 24 & I \\
$p q s B$ & 21 & 28 & III \\
$p q s C$ & 20 & 28 & III \\
$p q s D$ & 16 & 25 & III \\
$p q s E$ & 19 & 27 & III \\
$p q s H$ & 10 & 12 & I \\
$p q s R / m v f R$ & 14 & 11 & II \\
\hline
\end{tabular}

In reality, a global regulator has effects not only on a single QS gene but also on other QS genes through either direct or indirect pathway. For this consideration, we also have four scenarios: 1) both a global regulator and QS genes up-regulated (red number in Figure 5); 2) a global regulator up-regulated but QS genes down-regulated (blue number in Figure 5); 3) both a global regulator and QS genes down-regulated (blue number in Figure 6); and 4) a global regulator down-regulated but QS genes up-regulated (red number in Figure 6). These analyses can be done through counting the relevant gene 
Table 3. Grouping of up/down-regulations of genes that control AHL homeostasis according to their activity.

\begin{tabular}{cccc}
\hline Gene Name & Up-Regulations & Down-Regulations & Group \\
\hline mex $E$ & 18 & 16 & I \\
mex $F$ & 21 & 21 & I \\
$\operatorname{mex} G$ & 21 & 26 & III \\
$\operatorname{mex} H$ & 20 & 21 & I \\
mexI & 21 & 18 & I \\
opmD & 19 & 18 & I \\
oprN & 15 & 11 & II \\
pfm & 16 & 9 & II \\
pvdQ & 26 & 26 & I \\
quiP & 7 & 8 & I \\
\hline
\end{tabular}

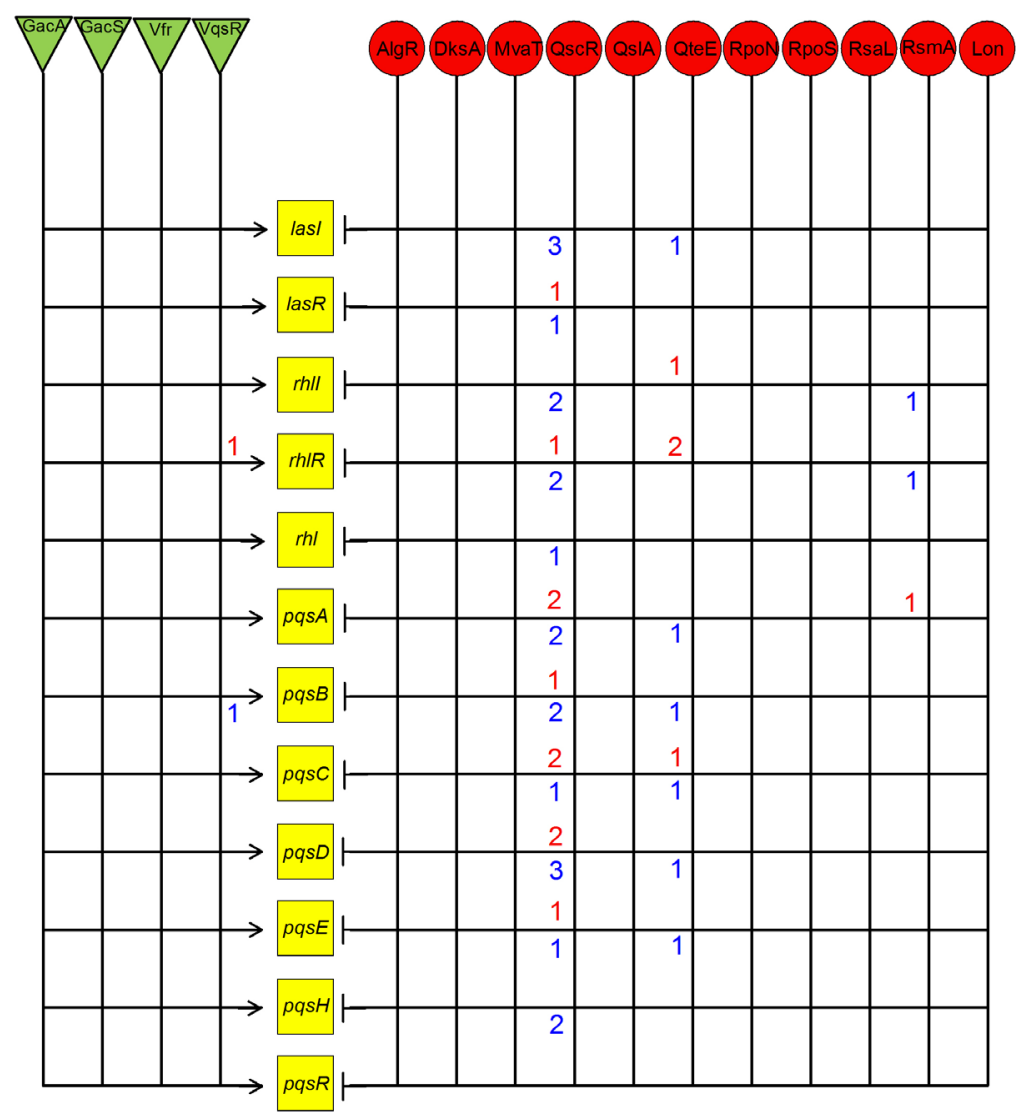

Figure 3. Frequency of up/down-regulation of QS genes in response to the up-regulation of a single global regulator with the rest global regulators unchanged. The red number above the horizontal line is the frequency of up-regulation of QS genes. The blue number below the horizontal line is the frequency of down-regulation of QS genes. Green triangles and red circles represent stimulating (arrow) and inhibiting (vertical-line end) global regulators, and yellow squares represent QS genes. 


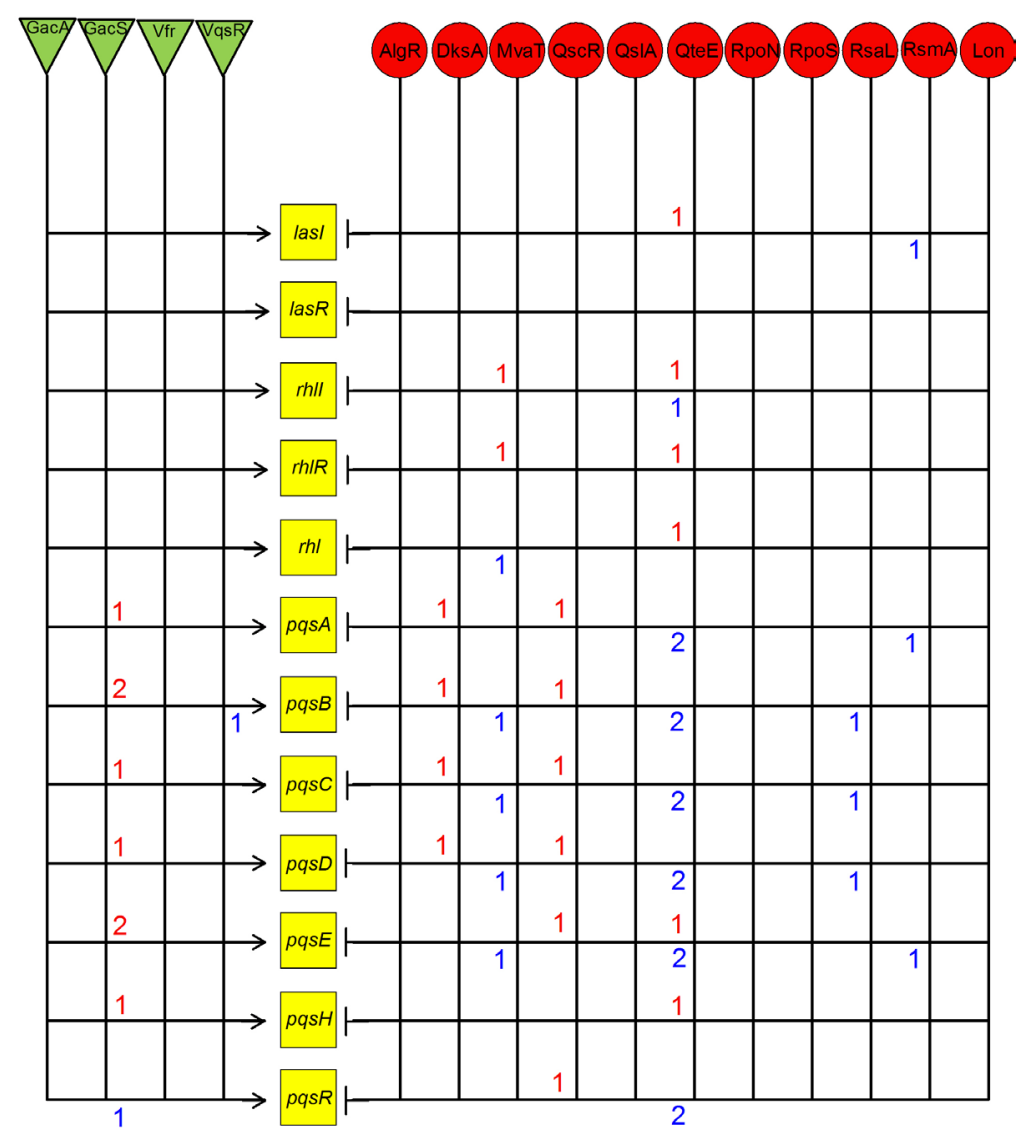

Figure 4. Frequency of up/down-regulation of QS genes in response to the down-regulation of a single global regulator with the rest global regulators unchanged (for the information on symbols and colors, refer to legend of Figure 3).

up/down-regulations in the four scenarios throughout all transcriptomic data, and then computing their probability. This probability is the chance that a global regulator impacts on QS genes.

Oppositely, a QS gene responds to global regulators differently. Similarly, we again have four scenarios: 1) both a QS gene and global regulators up-regulated (pink number in Figure 7), 2) a QS gene up-regulated but global regulators down-regulated (green number in Figure 7), 3) both a QS gene and global regulators down-regulated (green number in Figure 8), and 4) a QS gene down-regulated but global regulators up-regulated (pink number in Figure 8). The analysis procedure is exactly similar to the method for Figure 5 and Figure 6.

To conduct our study at population level with data from various sources, it is important to know the overlapped genes across different experimental conditions. If there are no overlapped genes, then we cannot combine all the datasets together for analysis. The experimental conditions in transcriptomic data from the 104 journal publications can be grouped into four types: 27 nutrition (starvation) related experiments, 38 stress related experiments, 14 habitat related experiments and 36 mutant related experiments. This analysis can be done through counting QS-related genes in each experiment and then using Venn diagram [62] to present the overlapped QS-related genes in Figure 9 and Figure 10.

\section{RESULTS AND DISCUSSION}

In this study, we combined the transcriptomic data from 104 journal publications in order to understand how QS-related genes function at population level in a quantitative manner. 


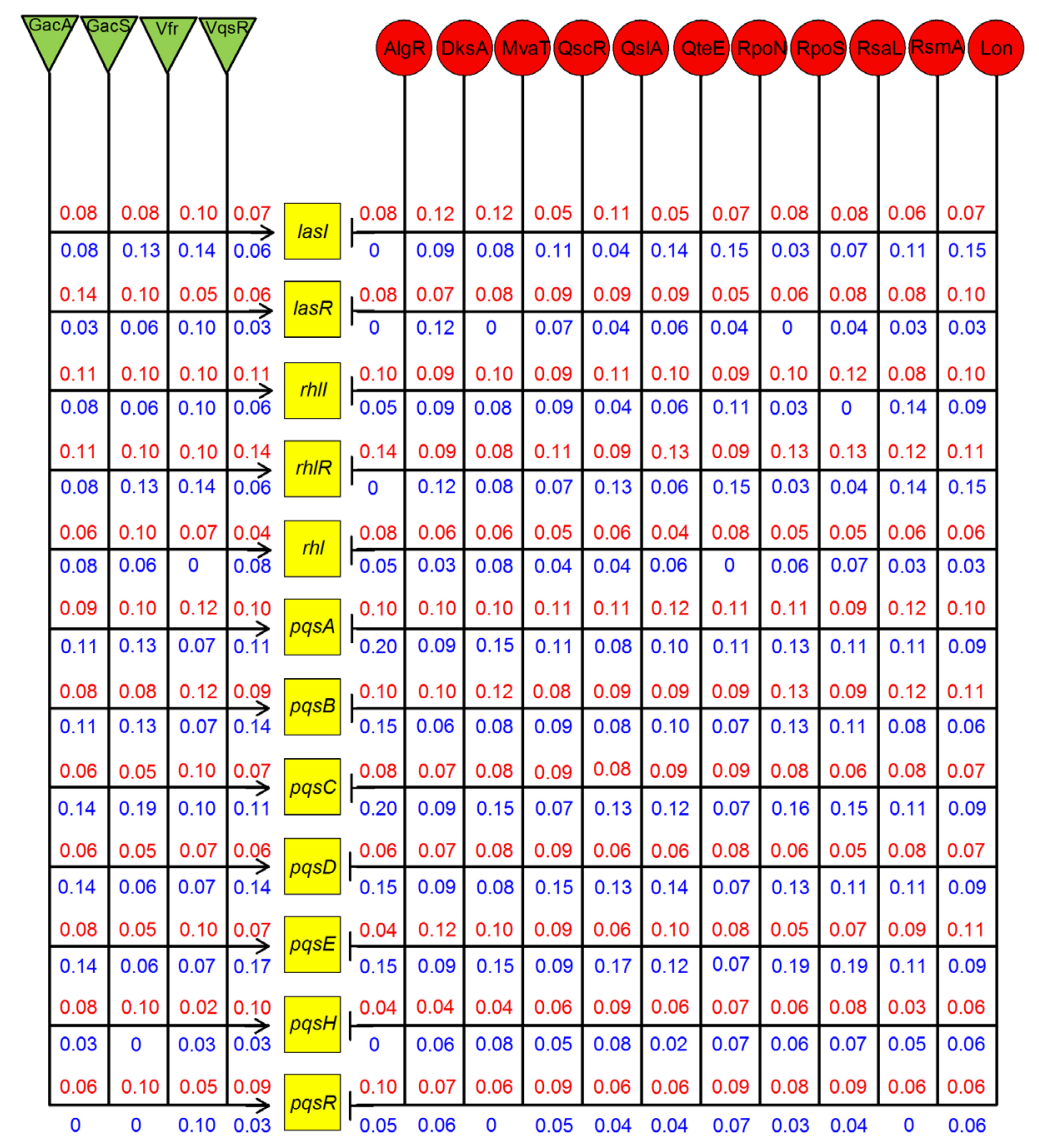

Figure 5. Probability that an up-regulated global regulator impacted on QS genes. Red number above horizontal line is the probability that a global regulator up-regulated QS genes. Blue number below horizontal line is the probability that a global regulator down-regulated QS genes. Green triangles and red circles represent stimulating (arrow) and inhibiting (vertical-line end) global regulators.

Figure 1 and Figure 2 show the activity of QS-related genes at population level in terms of symbol size, i.e. the larger the symbol size is, the stronger the gene's activity is. In Figure 1 and Figure 2, genes are arranged according to the cascade of QS gene regulatory mechanism, namely, global regulators (square symbols) regulate QS genes (triangle symbols), which then regulate QS-controlled genes (circle symbols), while AHL-acylases, enoyl-CoA reductase and import-export pumps (diamond symbols) adjust AHL homeostasis. Because most of the 104 studies were not specifically designed to investigate QS, so Figure 1 and 2 summarize the quantitative QS-related gene's activity under various experimental conditions.

The first striking feature in Figure 1 and Figure 2 is that the size of symbols varies differently, that is, the frequency of up/down-regulations is different. This is understandable because each gene has a different activity. Basically, we can determine a gene's role by comparing its frequency with others. For global regulators in up-regulation (Figure 1), RsmA with frequency of 24 is the most active, followed by Lon (with frequency of 20), RsaL and QteE (frequency of 17 for both). For global regulators in down-regulation (Figure 2), RsaL with frequency of 18 is the most active, followed by QslA with frequency of 17 and QteE with frequency of 15.

Interestingly, VqsR plays an equal role in both up-regulation (Figure 1) and down-regulation (Figure 2). This is possible because LasR directly binds to the promoter region of VqsR [65], and LasR is more 


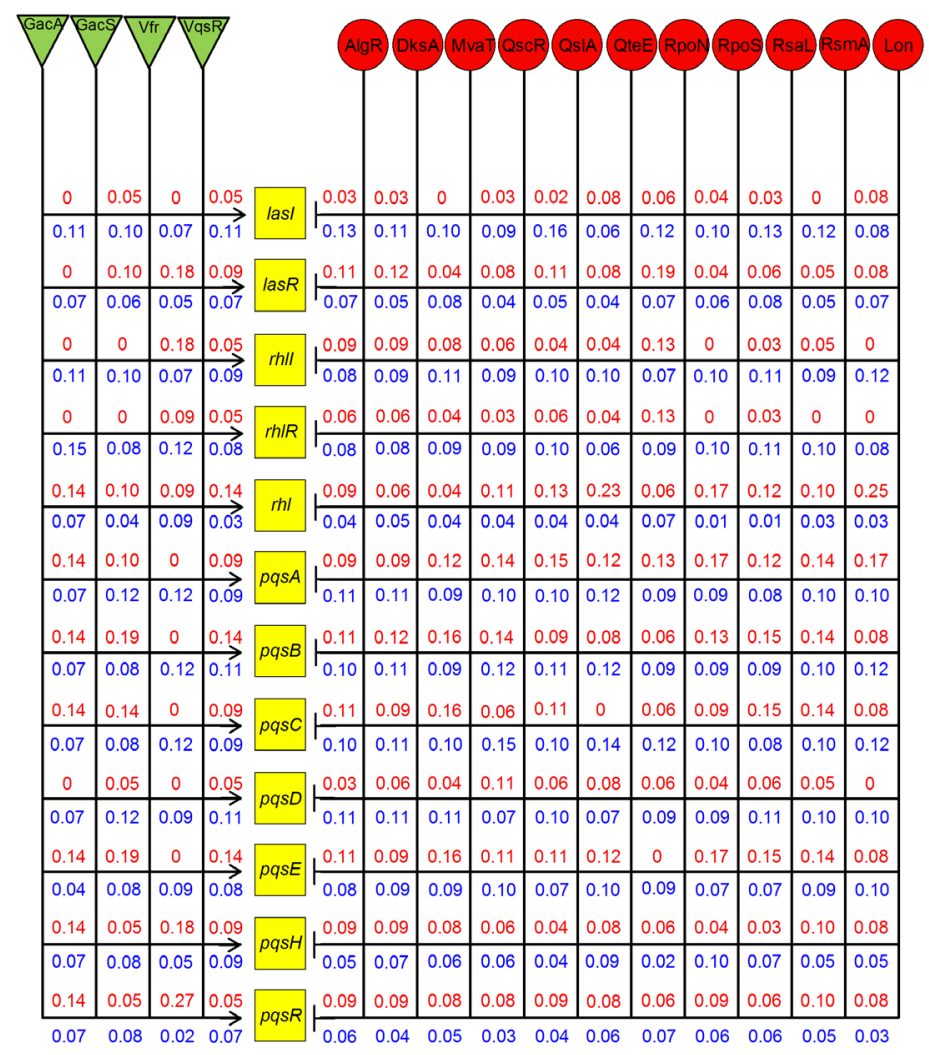

Figure 6. Probability that a down-regulated global regulator impacted on QS genes. Red number above horizontal line is the probability that a global regulator down-regulated but QS genes was up-regulated. Blue number below horizontal line is the probability that both global regulator and QS genes down-regulated. Green triangles and red circles represent stimulating (arrow) and inhibiting (vertical-line end) global regulators.

active in Figure 1, so more active VqsR in up-regulation would be due to that LasR promotes VqsR [65]. Similarly, QscR acted as the same as VqsR did in Figure 1 and Figure 2, which could be attributed to the fact that VqsR directly inhibits QscR [51].

Taking both up-regulation and down-regulation together into account, the global regulators can be classified into 3 groups according to their activity (Table 1). Group I includes DksA, QscR, QteE, RpoS, RsaL, Vfr and VqsR, which have an equal or somewhat equal activity in both up-regulation and downregulation. Group II includes Lon, RsmA and GacA, which have a stronger activity in up-regulation than in down-regulation. Group III includes AlgR2, MvaT, QslA, RpoN and GacS, which have a smaller activity in up-regulation than in down-regulation. This grouping provides useful information on access the activity of each global regulator because all global regulators were studied individually, so it is hard to know which one is more active than others.

For QS genes in up-regulation, pqsA with frequency of 25 is the most active, followed by $r h l R$ and $p q s B$ (frequency of 21 for both), and $p q s C$ with frequency of 20. For QS genes in downregulation, $p q s C$, $p q s B, p q s E, p q s D$ and $p q s A$ are more active because their frequency ranged from 28 to 24 . The QS genes can also be classified into 3 groups (column 4 in Table 2). Group I comprises $r h l l, p q s A$ and $p q s H$, which have an equal or somewhat equal activity in both up-regulation and down-regulation. Group II comprises lasR, $r h l R, r h l$ and $p q s R / m v f R$, which activate strongly in up-regulation. Group III comprises lasI, $p q s B$, $p q s C$, $p q s D$ and $p q s E$, which activate strongly in down-regulation. 


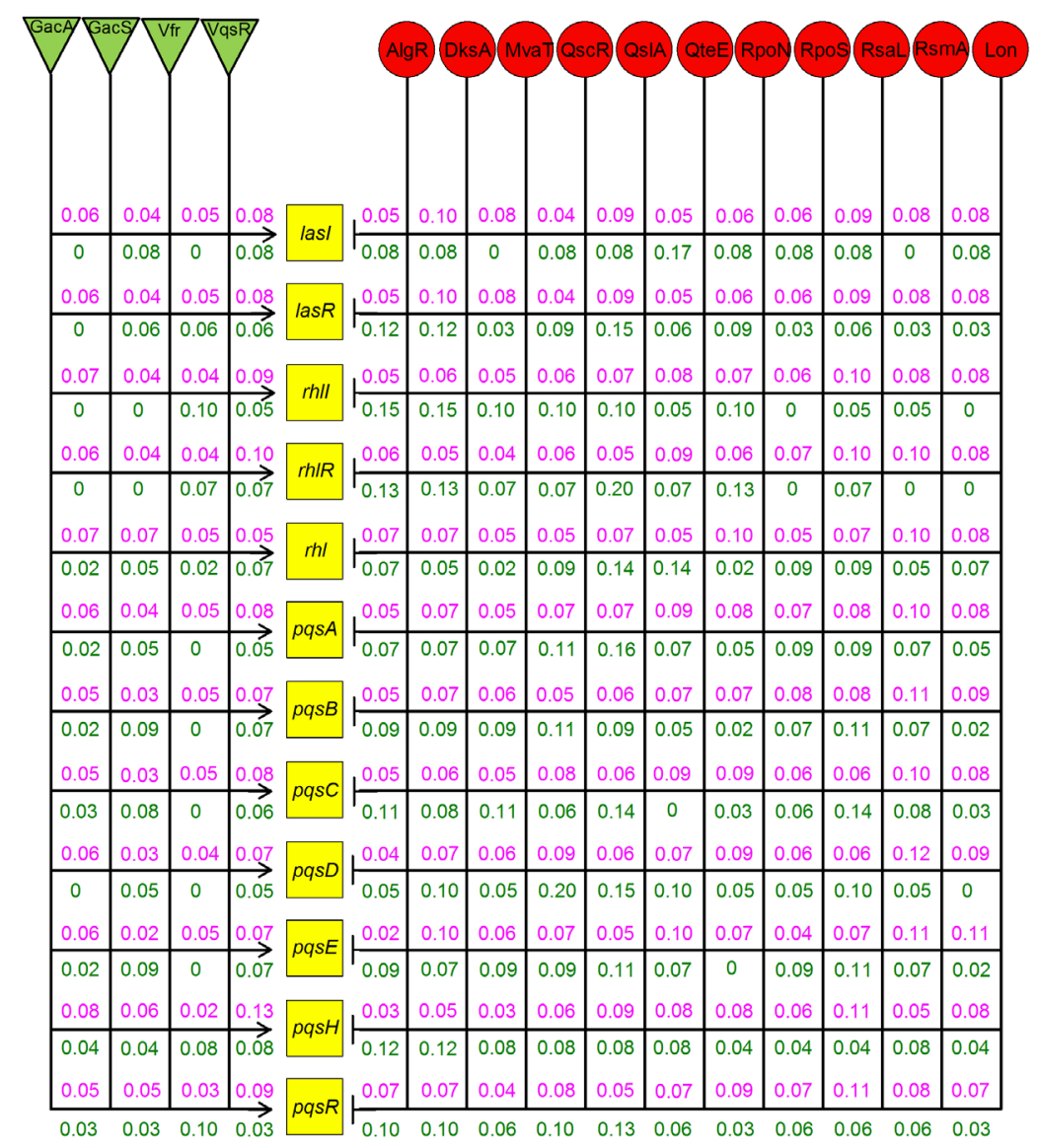

Figure 7. Probability that an up-regulated QS gene responded to global regulators. Pink number above horizontal line is the probability that both a QS gene and global regulators up-regulated. Green number below horizontal line is the probability that a QS gene up-regulated but global regulators downregulated. Green triangles and red circles represent stimulating (arrow) and inhibiting (vertical-line end) global regulators.

For the genes that control AHL homeostasis, $p v d Q$ is the most active with frequency of 26 in upregulation, followed by mex $F$ mex $G$ and $\operatorname{mex} I$ (frequency of 21 for each), and mex $H$ with frequency of 20. For these genes in down-regulation, $\operatorname{mex} G$ and $p v d Q$ are the most active (frequency of 26 for both), followed by mex $F$ and mexH (frequency of 21 for both). Similarly, these genes can be classified into 3 groups (column 4 in Table 3). Seven genes (mexE, mexF, mexH, mexI, opmD, pvdQ and quiP) belong to Group I with an equal or somewhat equal activity in both up-regulation and down-regulation. Two genes (oprN and $\mathrm{pfm}$ ) belong to Group II being more active in up-regulation than in down-regulation, which is plausible because enoyl-CoA reductase $(\mathrm{pfm})$ leads to an increase in autoinducer level rather than a decrease in autoinducer level [66]. Only one gene $(\operatorname{mex} G)$ belongs to Group III being less active in up-regulation than in down-regulation.

Collectively, Figure 1 and Figure 2 together with Tables 1-3 indicate which gene is more active at three different population levels. When QS-controlled genes are up-regulated, very active genes are as follows (norB, PA0515, norC, PA0525, PA4880, PA3235, narG, nirC, PA5481, PA5482, narH, PA1323, nirM, gcdH, PA2151, PA0510, coxB, PA2156, PA4739, narK1, PA2142, PA3913, nirF, PA0567, PA0714, PA1168, PA4139). When QS-controlled genes are down-regulated, very active genes are as follows (PA4306, phzD2, phzC2, phzE2, PA4131, hcnA, PA1869, PA4648, lasA, norC, PA1177, phzA1, hvn, PA0122, PA2372). 


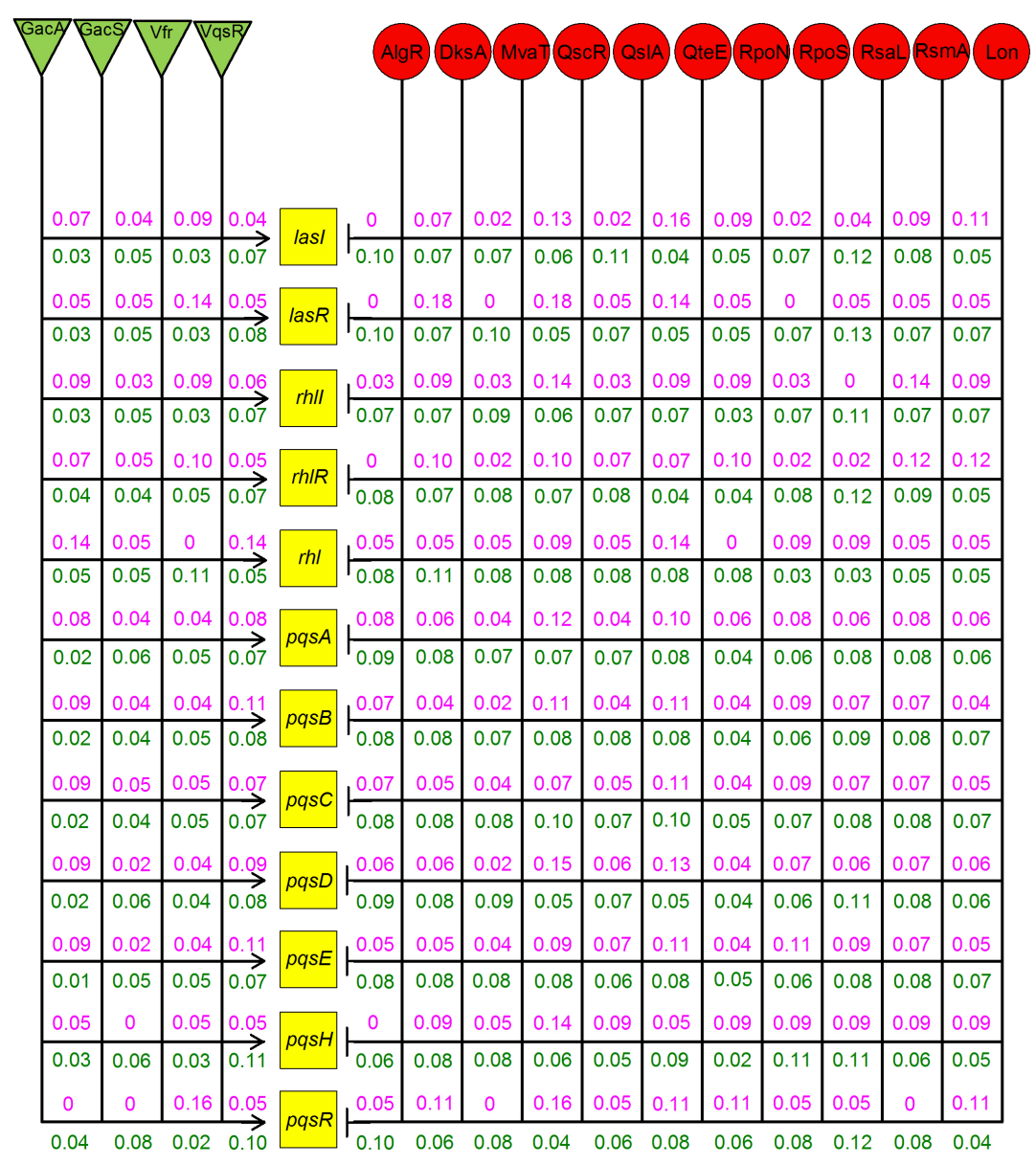

Figure 8. Probability that a down-regulated QS gene responded to global regulators. Pink number above horizontal line is the probability that a QS gene down-regulated but global regulators up-regulated. Green number below horizontal line is the probability that both a QS gene and global regulators down-regulated. Green triangles and red circles represent stimulating (arrow) and inhibiting (vertical-line end) global regulator.

The quantitatively hierarchical description of QS-related genes is the key point to reveal the underlining mechanism [67]. Individual studies often concentrate on pinpointing and finding out individual gene's regulatory mechanism. With numerous transcriptomic data, it is possible to build a hierarchical regulation of QS-related genes in a quantitative and precise way.

Figure 3 and Figure 4 show the frequencies of how QS genes reacted to the up/down-regulation of a single global regulator with the rest global regulators unchanged. These figures can be read as follows with respect to the colored numbers. For example, when VqsR up-regulated alone in Figure 3, it had a positive impact on $r h l R$ with frequency of 1 and a negative impact on $p q s B$ with frequency of 1 . At first glance, there are not many numbers in both Figure 3 and Figure 4, i.e. a single global regulator does not play a very big role in up/down-regulating QS genes when it acts alone. Of 15 global regulators, eleven in Figure 3 and seven in Figure 4 had no impact on QS genes when they acted alone. This once again demonstrates that global regulators are more likely to work together rather than alone. Comparing these two figures, we can find that there are more colored numbers in Figure 4 than in Figure 3, i.e. the down-regulation of a single global regulator impacted more on QS genes than its up-regulation did. As can be seen in Figure 4, DksA and QscR activated the expression of PQS-induced QS genes. On the contrary, VqsR repressed the 

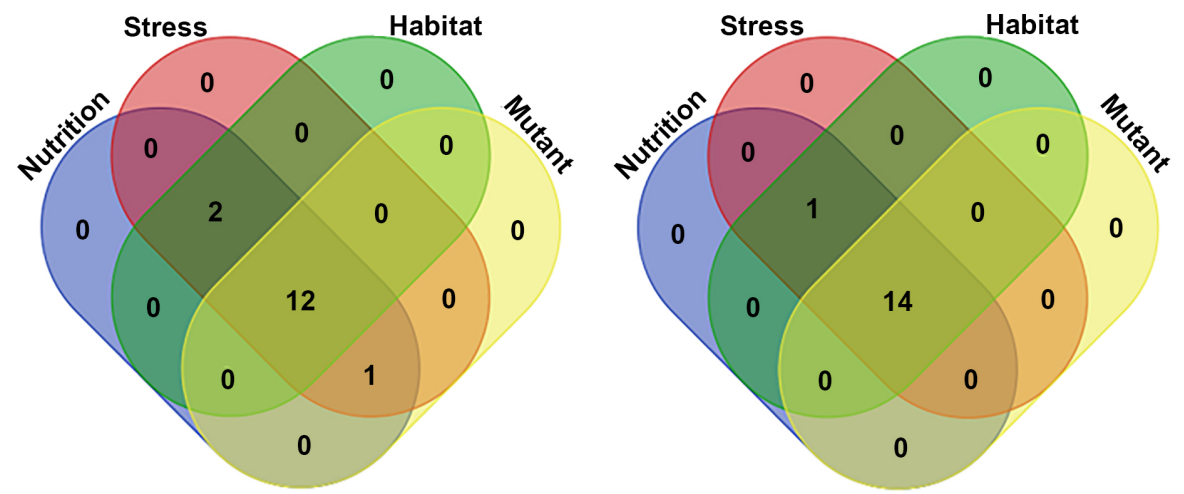

Figure 9. Overlap of global regulators in up-regulation (left panel) and down-regulation (right panel) under four types of experimental conditions.
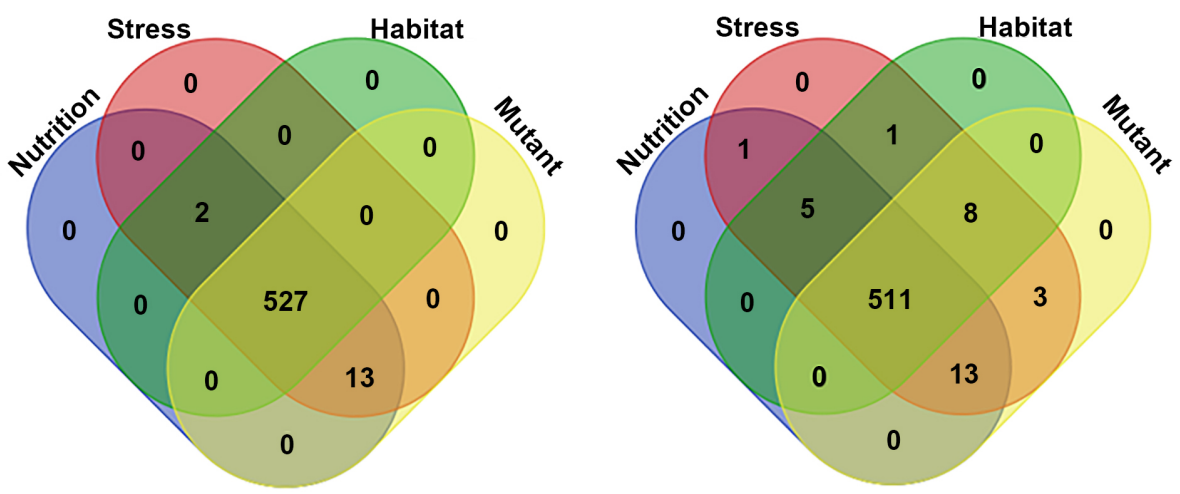

Figure 10. Overlap of QS-controlled genes in up-regulation (left panel) and down-regulation (right panel) under four types of experimental conditions.

expression of $p q s B$; RsaL repressed the expression of $p q s B$, $p q s C$ and $p q s D$; and RsmA repressed the expression of lasI, pqsA and pqsE.

Furthermore, some global regulators reveal different effects on different QS genes. For instance, when VqsR up-regulated, $r h l R$ was up-regulated but $p q s B$ down-regulated (Figure 3); when RsmA up-regulated, $r h l I$ and $r h l R$ were down-regulated but $p q s A$ was up-regulated (Figure 3); when GacS down-regulated, $p q s A$ to $p q s H$ were up-regulated but $p q s R$ was down-regulated (Figure 4); when MvaT down-regulated, $r h l I$ and $r h l R$ were up-regulated but $r h l, p q s B, p q s C, p q s D$ and $p q s E$ down-regulated (Figure 4). More complicated influence of single global regulator on QS genes can be found in the up-regulation of QscR and QteE (Figure 3) as well as in the down-regulation of QteE (Figure 4). Interestingly, a global regulator can play opposite roles in experiments because both red and blue numbers appeared for the same QS gene, for example, QscR impacted on lasR, rhlR, $p q s A, p q s B, p q s C, p q s D$ and $p q s E$ in Figure 3, and QteE impacted on rhll and $p q s E$ in Figure 4.

Previous studies demonstrated that QscR (PA1898) was a negative global regulator repressing LasI $[18,30]$. Recent works emphasize its role in the regulation of QS by affecting several AHLs [68], which highlights new strategies to treat bacterial infections $[69,70]$. More recently, a chromatin immunoprecipitation analysis demonstrates the mechanism of QscR to regulate QS, that is, QscR bounds to the promoter of a single operon for three genes PA1895 to PA1897, which link to $q s c R$ [71]. Here, our analysis shows that QscR alone has broad effects on QS genes. It is a real global regulator because it can repress not only on 
LasI-LasR system but also on RhlI-RhlR and PQS systems (blue numbers in QscR column in Figure 3). Meanwhile, it can activate three QS systems as indicated by the red numbers in the same column. Recently, experiments conformed that there is a regulatory link between $v q s R$ and $\mathrm{PQS}$, where RpoS plays an important role [72].

QteE, quorum threshold expression protein, displays active influence on QS in P. aeruginosa in both its alone up- and down-regulation. In general, this global regulator activates RhlI-RhlR systen but represses PQS system although dual effects can be found in some cases, including $r h l I, p q s C$ and $p q s E$ (Figure 3 and Figure 4). For LasI-LasR system, QteE negatively influences the activity of lasI but has no effect on lasR. Of course, there are overlaps in gene functions; for example, there is an overlap between QslA and QteE regulons, which affect the induction of 999 genes and the repression of 798 genes [73].

Figure 5 and Figure 6 display the probability that a global regulator impacted on QS genes. For example, considering the probability that GacA up-regulated QS genes (red numbers in the first column in Figure 5), GacA had the strongest impact on lasR with a probability of 0.14 , strong impact on rhlI and $r h I R$ with a probability of 0.11 for each, good impact on $p q s A$ with a probability of 0.9 , fair impact on lasI, $p q s B, p q s E$ and $p q s H$ with a probability of 0.08 for each, and weak impact on $r h l, p q s C, p q s D$ and $p q s E$ with a probability of 0.06 for each. In terms of the probability that GacA down-regulated QS genes (blue numbers), GacA has the strongest impact on $p q s C$, $p q s D$ and $p q s E$ with a probability of 0.14 for each, strong impact on $p q s A$ and $p q s B$ with a probability of 0.11 for each, fair impact on lasI, $r h l I, r h l R$ and $r h l$ with a probability of 0.08 for each, and weak impact on las $R$ and $p q s H$ with a probability of 0.03 but no impact on $p q s R$.

Similarly, let us look at how GacA impacts on QS genes during its down-regulation (see the first column in Figure 6). The blue numbers indicate similar effects of GacA on QS genes, that is, GacA down-regulated while QS genes are also down-regulated. GacA has strong impact on rhlR with a probability of 0.15 , good impact on lasI and $r h l I$ with a probability of 0.11 for each, fair impact on lasR, rhl, pqsA, $p q s B, p q s C, p q s D$ and $p q s H$ with a probability of 0.08 for each, and weak impact on $p q s E$ with a probability of 0.04 . On the contrary, red numbers show opposite effects of GacA on QS genes, that is, GacA down-regulated whereas QS genes are up-regulated. GacA affects strangely on $r h l, p q s A, p q s B, p q s C$, $p q s E$, $p q s H$ and $p q s R$ with a probability of 0.14 for each. However, it has no influence on lasI, lasR, rhlI, $r h I R$ and $p q s D$. In this manner, we have a probabilistic view of how a global regulator affects QS genes.

Figure 7 and Figure 8 display the probability that a QS gene responded to global regulators. For example, the probability that up-regulated lasI responded to up-regulated global regulators (pink numbers in the first row in Figure 7) ranges as follows: 0.10 for DksA, 0.09 for QslA and RsaL, 0.08 for MvaT, RsmA, Lon and VqsR, 0.06 for RpoN, RpoS and GacA, 0.05 for AlgR2, QteE and Vfr, 0.04 for QscR and GacS. The probability that up-regulated lasI responded to down-regulated global regulators (green numbers in the second row in Figure 7) ranges as follows: the strongest response to QteE had a probability of 0.17, and equal response to 8 global regulators (AlgR2, DksA, QscR, QslA, RpoN, RpoS, RsaL, Lon, GacS and VqsR) had a probability of 0.08 , but there was no response to 4 global regulators (MvaT, RsmA, GacA and Vfr).

Again taking lasI as an example, the probability of down-regulated lasI responding to up-regulated global regulators (pink numbers in the first row in Figure 8) ranges as follows: 0.16 for QteE, 0.13 for QscR, 0.10 for Lon, 0.09 for RpoN, RsmA and Vfr, 0.07 for DksA and GacA, 0.04 for RsaL, GacS and VqsR, 0.02 for MvaT, QslA and RpoS, and 0 for AlgR2. The probability of down-regulated lasI responding to down-regulated global regulators (green numbers in the second row in Figure 8) ranges as follows: 0.12 for RsaL, 0.11 for QslA, 0.10 for AlgR2, 0.08 for RsmA, 0.07 for 4 global regulators (DksA, MvaT, RpoS and VqsR), 0.06 for QscR, 0.05 for 3 global regulators (RpoN, Lon and GacS), 0.04 for QteE, and 0.03 for GacA and Vfr. In this manner, we get a probabilistic view of response of QS genes to global regulators.

Of those QS-related genes, some interesting points can be observed on global regulators, which in turn regulate QS genes. For example, LasR induces the expression of RsaL [35], which in turn inhibits QS system $[33,34]$, so this is a negative feedback loop. In addition, the LasR/OdDHL complex regulates VqsR 
[65], which in turn stimulates QS genes [27], so this is a positive feedback loop.

Collectively, Figures 5-8 demonstrate the interaction between global regulators and QS genes at population level. This interaction is balanced and weighed by different probabilities.

However, the quantitative regulation relationship between QS genes and QS-controlled genes cannot be presented in such a graphic manner due to the difficulties in drawing so many genes and lines. Grouping and stratifying of QS-controlled genes are needed for their analyses in future.

Figure 9 and Figure 10 illustrate the overlap of genes from global regulators and QS-controlled genes in up-regulation and down-regulation under four types of experimental conditions. In Figure 9, 12 (DksA, VqsR, QslA, MvaT, GacA, RpoS, RsaL, Lon, RsmA, QteE, QscR, RpoN) and 14 (DksA, VqsR, QslA, MvaT, RpoS, RsaL, Lon, RsmA, Vfr, QteE, QscR, GacS, AlgR2, RpoN) global regulator genes overlapped under four types of experimental conditions for up-regulation and down-regulation. This suggests that the activity of global regulators is rather independent of experimental conditions, and provides the evidence to combine all the transcriptomic data together. Yet, 2 (Vfr, AlgR2) and 1 (GacA) global regulators overlapped under three experimental conditions (nutrition, stress and habitat) for up-regulation and down-regulation, indicating that these three global regulators are less affected by mutation. For up-regulation, GacS appears under three experimental conditions (nutrition, stress and mutant), suggesting that it is less sensitive to habitat conditions.

Similarly, a vast majority of QS-controlled genes are independent of experimental conditions as demonstrated in Figure 10, where 527 and 511 QS-controlled genes overlapped under four types of experimental conditions for up-regulation and down-regulation. In addition, 2 and 5 QS-controlled genes overlapped under three types of experimental conditions (nutrition, stress and habitat), indicating that they are less sensitive to mutation; 13 QS-controlled genes overlapped under three types of experimental conditions (nutrition, stress and mutant) for both up-regulation and down-regulation, indicating that they are less affected by habitat conditions. Finally, 8 (stress, habitat and mutant), 3 (stress and mutant), 1 (nutrition and stress) and 1 (stress and habitat) QS-controlled genes overlapped in down-regulation (right panel in Figure 10), from which we can trace the common characteristics of these genes. For instance, $m o a E$ was down-regulated by nutrition and stress conditions whereas PA3242 was down-regulated by habitat and stress conditions. rfaE, PA0158 and PA3678 can be affected by mutants and stresses. Among 8 genes were down-regulated by stress, habitat and mutant, 3 genes, PA0567, PA1323 and PA3662, encode hypothetical proteins, which are free from the influence of nutrition.

In other words, what is the quantitatively regulatory mechanism of QS systems in $P$. aeruginosa. Clearly, the answer to this question is important because the first two QS systems in $P$. aeruginosa have close relationships with virulence [74], including following notorious virulence genes: lasB (PA3724) [75, 76], lasA (PA1871) [77, 78], toxA (PA1148) [79, 80], aprA (PA1249) [81], rhlA (PA3479), rhlB (PA3478) [82, 83], lecA (PA2570) [84], hcnA (PA2193), $h c n B$ (PA2194) and $h c n C$ (PA2195) [85], phzA (PA4210), phzB (PA4211), phzC (PA1901), phzD (PA1902), phzE (PA1903), phzF (PA1904), phzG (PA1905) and phzM (PA4209) [86-88]. The third QS system also has a relationship with virulence factors, e.g. pyocyanin [88], elastase, PA-IL lectin and rhamnolipids [7, 67, 89]. Usually, QS plays an important role in biofilm [90], and the signal molecules synthesized by QS systems affect eukaryote [91, 92]. Consequently, QS systems are considered as a target in therapy [93], although there are different viewpoints [94-97]. Indeed, the molecules with similar structures to AHL were intensively examined for their potential as antagonists to QS [98-100], and the development of inhibitors for QS is in therapeutic agendas [69, 70, 101].

In conclusion, it is well recognized that QS systems have very complicated regulatory mechanism at different levels in response to different stresses and stimuli. In this study, we concentrate our efforts on the general trend at population level rather than individual cases, which are heavily influenced and shadowed by various controllable and uncontrollable factors, by means of integrative analysis of transcriptomic datasets from 104 journal publications. The results provide not only quantitative information on how QS-related genes as whole behave in response to various stresses and stimuli at population level, but also the base to reveal some negative pathway which may reverse the QS process and thus reverse some clinical 
outcomes [102].

\section{FUND}

This study was partly supported by National Natural Science Foundation of China (31460296 and 31560315), Key Project of Guangxi Scientific Research and Technology Development Plan (AB17190534) and Special Funds for Building of Guangxi Talent Highland.

\section{CONFLICTS OF INTEREST}

The authors declare no conflicts of interest regarding the publication of this paper.

\section{REFERENCES}

1. Ohno-Machado, L. (2014) NIH's Big Data to Knowledge Initiative and the Advancement of Biomedical Informatics. Journal of the American Medical Informatics Association, 21, 193-193. https://doi.org/10.1136/amiajnl-2014-002666

2. Fuqua, W.C., Winans, S.C. and Greenberg, E.P. (1994) Quorum Sensing in Bacteria: The LuxR-LuxI Family of Cell Density-Responsive Transcriptional Regulators. Journal of Bacteriology, 176, 269-275. https://doi.org/10.1128/JB.176.2.269-275.1994

3. Salmond, G.P., Bycroft, B.W., Stewart, G.S. and Williams, P. (1995) The Bacterial "Enigma": Cracking the Code of Cell-Cell Communication. Molecular Microbiology, 16, 615-624. https://doi.org/10.1111/j.1365-2958.1995.tb02424.x

4. Fuqua, C., Winans, S.C. and Greenberg, E.P. (1996) Census and Consensus in Bacterial Ecosystems: The LuxR-LuxI Family of Quorum-Sensing Transcriptional Regulators. Annual Review of Microbiology, 50, 727-751. https://doi.org/10.1146/annurev.micro.50.1.727

5. Miller, M.B. and Bassler, B.L. (2001) Quorum Sensing in Bacteria. Annual Review of Microbiology, 55, 165-199. https://doi.org/10.1146/annurev.micro.55.1.165

6. Rahme, L.G., Tan, M.W., Le, L., Wong, S.M., Tompkins, R.G., Calderwood, S.B. and Ausubel, F.M. (1997) Use of Model Plant Hosts to Identify Pseudomonas aeruginosa Virulence Factors. Proceedings of the National Academy of Sciences of the United States of America, 94, 13245-13250. https://doi.org/10.1073/pnas.94.24.13245

7. Rahme, L.G., Ausubel, F.M., Cao, H., Drenkard, E., Goumnerov, B.C., Lau, G.W., Mahajan-Miklos, S., Plotnikova, J., Tan, MW., Tsongalis, J., Walendziewicz, C.L. and Tompkins, R.G. (2000) Plants and Animals Share Functionally Common Bacterial Virulence Factors. Proceedings of the National Academy of Sciences of the United States of America, 97, 8815-8821. https://doi.org/10.1073/pnas.97.16.8815

8. Pearson, J.P., Gray, K.M., Passador, L., Tucker, K.D., Eberhard, A., Iglewski, B.H. and Greenberg, E.P. (1994) Structure of the Autoinducer Required for Expression of Pseudomonas aeruginosa Virulence Genes. Proceedings of the National Academy of Sciences of the United States of America, 91, 197-201. https://doi.org/10.1073/pnas.91.1.197

9. Manos, J., Arthur, J., Rose, B., Tingpej, P., Fung, C., Curtis, M., Webb, J.S., Hu, H., Kjelleberg, S., Gorrell, M.D., Bye, P. and Harbour, C. (2008) Transcriptome Analyses and Biofilm-Forming Characteristics of a Clonal Pseudomonas aeruginosa from the Cystic Fibrosis Lung. Journal of Medical Microbiology, 57, 1454-1465. https://doi.org/10.1099/jmm.0.2008/005009-0

10. Manos, J., Arthur, J., Rose, B., Bell, S., Tingpej, P., Hu, H., Webb, J., Kjelleberg, S., Gorrell, M.D., Bye, P. and Harbour, C. (2009) Gene Expression Characteristics of a Cystic Fibrosis Epidemic Strain of Pseudomonas aeruginosa during Biofilm and Planktonic Growth. FEMS Microbiology Letters, 292, 107-114. 
https://doi.org/10.1111/j.1574-6968.2008.01472.x

11. Pearson, J.P., Passador, L., Iglewski, B.H. and Greenberg, E.P. (1995) A Second N-acylhomoserine Lactone Signal Produced by Pseudomonas aeruginosa. Proceedings of the National Academy of Sciences of the United States of America, 92, 1490-1494. https://doi.org/10.1073/pnas.92.5.1490

12. Pesci, E.C., Pearson, J.P., Seed, P.C. and Iglewski, B.H. (1997) Regulation of las and rhl Quorum Sensing in Pseudomonas aeruginosa. Journal of Bacteriology, 179, 3127-3132.

https://doi.org/10.1128/JB.179.10.3127-3132.1997

13. Mashburn-Warren, L., Howe, J., Garidel, P., Richter, W., Steiniger, F., Roessle, M., Brandenburg, K. and Whiteley, M. (2008) Interaction of Quorum Signals with Outer Membrane Lipids: Insights into Prokaryotic Membrane Vesicle Formation. Molecular Microbiology, 69, 491-502. https://doi.org/10.1111/j.1365-2958.2008.06302.x

14. Kulkarni, H.M. and Jagannadham, M.V. (2014) Biogenesis and Multifaceted Roles of Outer Membrane Vesicles from Gram-Negative Bacteria. Microbiology, 160, 2109-2121. https://doi.org/10.1099/mic.0.079400-0

15. Schuster, M. and Greenberg, E.P. (2006) A Network of Networks: Quorum-Sensing Gene Regulation in Pseudomonas aeruginosa. International Journal of Medical Microbiology, 296, 73-81. https://doi.org/10.1016/j.ijmm.2006.01.036

16. Williams, P. and Cámara, M. (2009) Quorum Sensing and Environmental Adaptation in Pseudomonas aeruginosa: A Tale of Regulatory Networks and Multifunctional Signal Molecules. Current Opinion in Microbiology, 12, 182-191. https://doi.org/10.1016/j.mib.2009.01.005

17. Lee, J. and Zhang, L. (2015) The Hierarchy Quorum Sensing Network in Pseudomonas aeruginosa. Protein \& Cell, 6, 26-41. https://doi.org/10.1007/s13238-014-0100-x

18. Latifi, A., Foglino, M., Tanaka, K., Williams, P. and Lazdunski, A. (1996) A Hierarchical Quorum-Sensing Cascade in Pseudomonas aeruginosa Links the Transcriptional Activators LasR and RhIR (VsmR) to Expression of the Stationary-Phase Sigma Factor RpoS. Molecular Microbiology, 21, 1137-1146.

https://doi.org/10.1046/j.1365-2958.1996.00063.x

19. Pesci, E.C., Milbank, J.B., Pearson, J.P., McKnight, S., Kende, A.S., Greenberg, E.P. and Iglewski, B.H. (1999) Quinolone Signaling in the Cell-to-Cell Communication System of Pseudomonas aeruginosa. Proceedings of the National Academy of Sciences of the United States of America, 96, 11229-11234.

https://doi.org/10.1073/pnas.96.20.11229

20. Schertzer, J.W., Boulette, M.L. and Whiteley, M. (2009) More than a Signal: Non-Signaling Properties of Quorum Sensing Molecules. Trends in Microbiology, 17, 189-195. https://doi.org/10.1016/j.tim.2009.02.001

21. McKnight, S.L., Iglewski, B.H. and Pesci, E.C. (2000) The Pseudomonas Quinolone Signal Regulates rhl Quorum-Sensing in Pseudomonas aeruginosa. Journal of Bacteriology, 182, 2702-2708.

https://doi.org/10.1128/JB.182.10.2702-2708.2000

22. Wade, D.S., Calfee, M.W., Rocha, E.R., Ling, E.A., Engstrom, E., Coleman, J.P. and Pesci, E.C. (2005) Regulation of Pseudomonas Quinolone Signal Synthesis in Pseudomonas aeruginosa. Journal of Bacteriology, 187, 4372-4380. https://doi.org/10.1128/JB.187.13.4372-4380.2005

23. Siehnel, R., Traxler, B., An, D.D., Parsek, M.R., Schaefer, A.L. and Singh, P.K. (2010) A Unique Regulator Controls the Activation Threshold of Quorum-Regulated Genes in Pseudomonas aeruginosa. Proceedings of the National Academy of Sciences of the United States of America, 107, 7916-7921.

https://doi.org/10.1073/pnas.0908511107

24. Piper, K.R. and Farrand, S.K. (2000) Quorum Sensing but Not Autoinduction of Ti Plasmid Conjugal Transfer Requires Control by the Opine Regulon and the Antiactivator TraM. Journal of Bacteriology, 182, 1080-1088. https://doi.org/10.1128/JB.182.4.1080-1088.2000 
25. Diggle, S.P., Winzer, K., Lazdunski, A., Williams, P. and Camara, M. (2002) Advancing the Quorum in Pseudomonas aeruginosa: MvaT and the Regulation of N-Acylhomoserine Lactone Production and Virulence Gene Expression. Journal of Bacteriology, 184, 2576-2586. https://doi.org/10.1128/JB.184.10.2576-2586.2002

26. Heurlier, K., Dénervaud, V., Pessi, G., Reimmann, C. and Haas, D. (2003) Negative Control of Quorum Sensing by RpoN ( $\sigma 54)$ in Pseudomonas aeruginosa PAO1. Journal of Bacteriology, 185, 2227-2235.

https://doi.org/10.1128/JB.185.7.2227-2235.2003

27. Juhas, M., Wiehlmann, L., Huber, B., Jordan, D., Lauber, J., Salunkhe, P., Limpert, A.S., von Götz, F., Steinmetz, I., Eberl, L. and Tümmler, B. (2004) Global Regulation of Quorum Sensing and Virulence by VqsR in Pseudomonas aeruginosa. Microbiology, 150, 831-841. https://doi.org/10.1099/mic.0.26906-0

28. Ledgham, F., Soscia, C., Chakrabarty, A., Lazdunski, A. and Foglino, M. (2003) Global Regulation in Pseudomonas aeruginosa: The Regulatory Protein AlgR2 (AlgQ) Acts as a Modulator of Quorum Sensing. Research in Microbiology, 154, 207-213. https://doi.org/10.1016/S0923-2508(03)00024-X

29. Thompson, L.S., Webb, J.S., Rice, S.A. and Kjelleberg, S. (2003) The Alternative Sigma Factor RpoN Regulates the Quorum Sensing Gene rhlI in Pseudomonas aeruginosa. FEMS Microbiology Letters, 220, 187-195.

https://doi.org/10.1016/S0378-1097(03)00097-1

30. Chugani, S.A., Whiteley, M., Lee, K.M., D’Argenio, D., Manoil, C. and Greenberg, E.P. (2001) QscR, a Modulator of Quorum-Sensing Signal Synthesis and Virulence in Pseudomonas aeruginosa. Proceedings of the National Academy of Sciences of the United States of America, 98, 2752-2757. https://doi.org/10.1073/pnas.051624298

31. Seet, Q. and Zhang, L.H. (2011) Anti-Activator QslA Defines the Quorum Sensing Threshold and Response in Pseudomonas aeruginosa. Molecular Microbiology, 80, 951-965.

https://doi.org/10.1111/j.1365-2958.2011.07622.x

32. Fan, H., Dong, Y., Wu, D., Bowler, M.W., Zhang, L. and Song, H. (2013) QsIA Disrupts LasR Dimerization in Antiactivation of Bacterial Quorum Sensing. Proceedings of the National Academy of Sciences of the United States of America, 110, 20765-20770. https://doi.org/10.1073/pnas.1314415110

33. de Kievit, T., Seed, P.C., Nezezon, J., Passador, L. and Iglewski, B.H. (1999) RsaL, a Novel Repressor of Virulence Gene Expression in Pseudomonas aeruginosa. Journal of Bacteriology, 181, 2175-2184.

https://doi.org/10.1128/JB.181.7.2175-2184.1999

34. Venturi, V., Rampioni, G., Pongor, S. and Leoni, L. (2011) The Virtue of Temperance: Built-In Negative Regulators of Quorum Sensing in Pseudomonas. Molecular Microbiology, 82, 1060-1070.

https://doi.org/10.1111/j.1365-2958.2011.07890.x

35. Rampioni, G., Schuster, M., Greenberg, E.P., Bertani, I., Grasso, M., Venturi, V., Zennaro, E. and Leoni, L. (2007) RsaL Provides Quorum Sensing Homeostasis and Functions as a Global Regulator of Gene Expression in Pseudomonas aeruginosa. Molecular Microbiology, 66, 1557-1565.

https://doi.org/10.1111/j.1365-2958.2007.06029.x

36. Rampioni, G., Schuster, M., Greenberg, E.P., Zennaro, E. and Leoni, L. (2009) Contribution of the RsaL Global Regulator to Pseudomonas aeruginosa Virulence and Biofilm Formation. FEMS Microbiology Letters, 301, 210-217. https://doi.org/10.1111/j.1574-6968.2009.01817.x

37. Pessi, G., Williams, F., Hindle, Z., Heurlier, K., Holden, M.T., Cámara, M., Haas, D. and Williams, P. (2001) The Global Posttranscriptional Regulator RsmA Modulates Production of Virulence Determinants and N-Acylhomoserine Lactones in Pseudomonas aeruginosa. Journal of Bacteriology, 183, 6676-6683.

https://doi.org/10.1128/JB.183.22.6676-6683.2001

38. Branny, P., Pearson, J.P., Pesci, E.C., Kohler, T., Iglewski, B.H. and Van Delden, C. (2001) Inhibition of Quorum Sensing by a Pseudomonas aeruginosa dksA Homologue. Journal of Bacteriology, 183, 1531-1539.

https://doi.org/10.1128/JB.183.5.1531-1539.2001 
39. van Delden, C., Comte, R. and Bally, A.M. (2001) Stringent Response Activates Quorum Sensing and Modulates Cell Density-Dependent Gene Expression in Pseudomonas aeruginosa. Journal of Bacteriology, 183, 5376-5384. https://doi.org/10.1128/JB.183.18.5376-5384.2001

40. Jude, F., Köhler, T., Branny, P., Perron, K., Mayer, M.P., Comte, R. and van Delden, C. (2003) Posttranscriptional Control of Quorum-Sensing-Dependent Virulence Genes by DksA in Pseudomonas aeruginosa. Journal of Bacteriology, 185, 3558-3566. https://doi.org/10.1128/JB.185.12.3558-3566.2003

41. Brint, J.M. and Ohman, D.E. (1995) Synthesis of Multiple Exoproducts in Pseudomonas aeruginosa Is under the Control of RhlR-RhlI, Another Set of Regulators in Strain PAO1 with Homology to the Autoinducer-Responsive LuxR-LuxI Family. Journal of Bacteriology, 177, 7155-7163. https://doi.org/10.1128/JB.177.24.7155-7163.1995

42. Takaya, A., Tabuchi, F., Tsuchiya, H., Isogai, E. and Yamamoto, T. (2008) Negative Regulation of Quorum-Sensing Systems in Pseudomonas aeruginosa by ATP-Dependent Lon Protease. Journal of Bacteriology, 190, 4181-4188. https://doi.org/10.1128/JB.01873-07

43. Whiteley, M., Lee, K.M. and Greenberg, E.P. (1999) Identification of Genes Controlled by Quorum Sensing in Pseudomonas aeruginosa. Proceedings of the National Academy of Sciences of the United States of America, 96, 13904-13909. https://doi.org/10.1073/pnas.96.24.13904

44. Whiteley, M., Parsek, M.R. and Greenberg, E.P. (2000) Regulation of Quorum Sensing by RpoS in Pseudomonas aeruginosa. Journal of Bacteriology, 182, 4356-4360. https://doi.org/10.1128/JB.182.15.4356-4360.2000

45. Schuster, M., Hawkins, A.C., Harwood, C.S. and Greenberg, E.P. (2004) The Pseudomonas aeruginosa RpoS Regulon and Its Relationship to Quorum Sensing. Molecular Microbiology, 51, 973-985. https://doi.org/10.1046/j.1365-2958.2003.03886.x

46. Reimmann, C., Beyeler, M., Latifi, A., Winteler, H., Foglino, M., Lazdunski, A. and Haas, D. (1997) The Global Activator GacA of Pseudomonas aeruginosa PAO Positively Controls the Production of the Autoinducer N-Butyryl-Homoserine Lactone and the Formation of the Virulence Factors Pyocyanin, Cyanide and Lipase. Molecular Microbiology, 24, 309-319. https://doi.org/10.1046/j.1365-2958.1997.3291701.x

47. Parkins, M.D., Ceri, H. and Storey, D.G. (2001) Pseudomonas aeruginosa GacA, a Factor in Multihost Virulence, Is Also Essential for Biofilm Formation. Molecular Microbiology, 40, 1215-1226. https://doi.org/10.1046/j.1365-2958.2001.02469.x

48. Bertani, I. and Venturi, V. (2004) Regulation of the N-Acyl Homoserine Lactone-Dependent Quorum-Sensing System in Rhizosphere Pseudomonas putida WCS358 and Cross-Talk with the Stationary-Phase RpoS Sigma Factor and the Global Regulator GacA. Applied and Environmental Microbiology, 70, 5493-5502. https://doi.org/10.1128/AEM.70.9.5493-5502.2004

49. Albus, A.M., Pesci, E.C., Runyen-Janecky, L.J., West, S.E. and Iglewski, B.H. (1997) Vfr Controls Quorum Sensing in Pseudomonas aeruginosa. Journal of Bacteriology, 179, 3928-3935.

https://doi.org/10.1128/JB.179.12.3928-3935.1997

50. Dong, Y.H., Zhang, X.F., Xu, J.L., Tan, A.T. and Zhang, L.H. (2005) VqsM, a Novel AraC-Type Global Regulator of Quorum-Sensing Signalling and Virulence in Pseudomonas aeruginosa. Molecular Microbiology, 58, 552-564. https://doi.org/10.1111/j.1365-2958.2005.04851.x

51. Liang, H., Deng, X., Ji, Q., Sun, F., Shen, T. and He, C. (2012) The Pseudomonas aeruginosa Global Regulator VqsR Directly Inhibits QscR to Control Quorum-Sensing and Virulence Gene Expression. Journal of Bacteriology, 194, 3098-3108. https://doi.org/10.1128/JB.06679-11

52. Gambello, M.J., Kaye, S. and Iglewski, B.H. (1993) LasR of Pseudomonas aeruginosa Is a Transcriptional Activator of the Alkaline Protease Gene (apr) and an Enhancer of Exotoxin a Expression. Infection and Immunity, 61, 1180-1184. https://doi.org/10.1128/IAI.61.4.1180-1184.1993 
53. Wagner, V.E., Bushnell, D., Passador, L., Brooks, A.I. and Iglewski, B.H. (2003) Microarray Analysis of Pseudomonas aeruginosa Quorum-Sensing Regulons: Effects of Growth Phase and Environment. Journal of Bacteriology, 185, 2080-2095. https://doi.org/10.1128/JB.185.7.2080-2095.2003

54. Huang, J.J., Petersen, A., Whiteley, M. and Leadbetter, J.R. (2006) Identification of QuiP, the Product of Gene PA1032, as the Second Acyl-Homoserine Lactone Acylase of Pseudomonas aeruginosa PAO1. Applied and Environmental Microbiology, 72, 1190-1197. https://doi.org/10.1128/AEM.72.2.1190-1197.2006

55. Sio, C.F., Otten, L.G., Cool, R.H., Diggle, S.P., Braun, P.G., Bos, R., Daykin, M., Cámara, M., Williams, P. and Quax, W.J. (2006) Quorum Quenching by an N-Acyl-Homoserine Lactone Acylase from Pseudomonas aeruginosa PAO1. Infection and Immunity, 74, 1673-1682. https://doi.org/10.1128/IAI.74.3.1673-1682.2006

56. Kohler, T., van Delden, C., Curty, L.K., Hamzehpour, M.M. and Pechere, J.C. (2001) Overexpression of the MexEF-OprN Multidrug Efflux System Affects Cell-to-Cell Signaling in Pseudomonas aeruginosa. Journal of Bacteriology, 183, 5213-5222. https://doi.org/10.1128/JB.183.18.5213-5222.2001

57. Aendekerk, S., Ghysels, B., Cornelis, P. and Baysse, C. (2002) Characterization of a New Efflux Pump, MexGHIOpmD, from Pseudomonas aeruginosa That Confers Resistance to Vanadium. Microbiology, 148, 2371-2381. https://doi.org/10.1099/00221287-148-8-2371

58. Mou, R., Bai, F., Duan, Q., Wang, X., Xu, H., Bai, Y., Zhang, X., Jin, S. and Qiao, M. (2011) Mutation of pfm Affects the Adherence of Pseudomonas aeruginosa to Host Cells and the Quorum Sensing System. FEMS Microbiology Letters, 324, 173-180. https://doi.org/10.1111/j.1574-6968.2011.02401.x

59. Schuster, M., Lostroh, C., Ogi, T. and Greenberg, E.P. (2003) Identification, Timing and Signal Specificity of Pseudomonas aeruginosa Quorum-Controlled Genes: A Transcriptome Analysis. Journal of Bacteriology, 185, 2066-2079. https://doi.org/10.1128/JB.185.7.2066-2079.2003

60. Edgar, R., Domrachev, M. and Lash, A.E. (2002) Gene Expression Omnibus: NCBI Gene Expression and Hybridization Array Data Repository. Nucleic Acids Research, 30, 207-210. https://doi.org/10.1093/nar/30.1.207

61. Barrett, T., Wilhite, S.E., Ledoux, P., Evangelista, C., Kim, I.F., Tomashevsky, M., Marshall, K.A., Phillippy, K.H., Sherman, P.M., Holko, M., Yefanov, A., Lee, H., Zhang, N., Robertson, C.L., Serova, N., Davis, S. and Soboleva, A. (2013) NCBI GEO: Archive for Functional Genomics Data Sets-Update. Nucleic Acids Research, 41, D991-D995. https://doi.org/10.1093/nar/gks1193

62. http://bioinformatics.psb.ugent.be/webtools/Venn

63. Winsor, G.L., Lam, D.K., Fleming, L., Lo, R., Whiteside, M.D., Yu, N.Y., Hancock, R.E. and Brinkman, F.S. (2011) Pseudomonas Genome Database: Improved Comparative Analysis and Population Genomics Capability for Pseudomonas Genomes. Nucleic Acids Research, 39, D596-D600. https://doi.org/10.1093/nar/gkq869

64. Winsor, G.L., Griffiths, E.J., Lo, R., Dhillon, B.K., Shay, J.A. and Brinkman, F.S. (2016) Enhanced Annotations and Features for Comparing Thousands of Pseudomonas Genomes in the Pseudomonas Genome Database. Nucleic Acids Research, 44, D646-D653. https://doi.org/10.1093/nar/gkv1227

65. Li, L.L., Malone, J.E. and Iglewski, B.H. (2007) Regulation of the Pseudomonas aeruginosa Quorum-Sensing Regulator VqsR. Journal of Bacteriology, 189, 4367-4374. https://doi.org/10.1128/JB.00007-07

66. Yuan, A.H., Gregory, B.D., Sharp, J.S., McCleary, K.D., Dove, S.L. and Hochschild, A. (2008) Rsd Family Proteins Make Simultaneous Interactions with Regions 2 and 4 of the Primary Sigma Factor. Molecular Microbiology, 70, 1136-1151. https://doi.org/10.1111/j.1365-2958.2008.06462.x

67. Liu, Y.C., Chan, K.G. and Chang, C.Y. (2015) Modulation of Host Biology by Pseudomonas aeruginosa Quorum Sensing Signal Molecules: Messengers or Traitors. Frontiers in Microbiology, 6, 1226. https://doi.org/10.3389/fmicb.2015.01226

68. Chugani, S. and Greenberg, E.P. (2014) An Evolving Perspective on the Pseudomonas aeruginosa Orphan 
Quorum Sensing Regulator QscR. Frontiers in Cellular and Infection Microbiology, 4, 152.

https://doi.org/10.3389/fcimb.2014.00152

69. Weng, L.X., Yang, Y.X., Zhang, Y.Q. and Wang, L.H. (2014) A New Synthetic Ligand That Activates QscR and Blocks Antibiotic-Tolerant Biofilm Formation in Pseudomonas aeruginosa. Applied Microbiology and Biotechnology, 98, 2565-2572. https://doi.org/10.1007/s00253-013-5420-x

70. Wysoczynski-Horita, C.L., Boursier, M.E., Hill, R., Hansen, K., Blackwell, H.E. and Churchill, M.E.A. (2018) Mechanism of Agonism and Antagonism of the Pseudomonas aeruginosa Quorum Sensing Regulator QscR with Non-Native Ligands. Molecular Microbiology, 108, 240-257. https://doi.org/10.1111/mmi.13930

71. Ding, F., Oinuma, K.I., Smalley, N.E., Schaefer, A.L., Hamwy, O., Greenberg, E.P. and Dandekar, A.A. (2018) The Pseudomonas aeruginosa Orphan Quorum Sensing Signal Receptor QscR Regulates Global Quorum Sensing Gene Expression by Activating a Single Linked Operon. MBio, 9, pii: e01274-18. https://doi.org/10.1128/mBio.01274-18

72. Viducic, D., Murakami, K., Amoh, T., Ono, T. and Miyake, Y. (2017) Role of the Interplay between Quorum Sensing Regulator VqsR and the Pseudomonas Quinolone Signal in Mediating Carbapenem Tolerance in Pseudomonas aeruginosa. Research in Microbiology, 168, 450-460. https://doi.org/10.1016/j.resmic.2017.02.007

73. Asfahl, K.L. and Schuster, M. (2018) Additive Effects of Quorum Sensing Anti-Activators on Pseudomonas aeruginosa Virulence Traits and Transcriptome. Frontiers in Microbiology, 8, 2654.

https://doi.org/10.3389/fmicb.2017.02654

74. Cao, H., Krishnan, G., Goumnerov, B., Tsongalis, J., Tompkins, R. and Rahme, L.G. (2001) A Quorum Sensing-Associated Virulence Gene of Pseudomonas aeruginosa Encodes a LysR-Like Transcription Regulator with a Unique Self-Regulatory Mechanism. Proceedings of the National Academy of Sciences of the United States of America, 98, 14613-14618. https://doi.org/10.1073/pnas.251465298

75. Wolz, C., Hohloch, K., Ocaktan, A., Poole, K., Evans, R.W., Rochel, N., Albrecht-Gary, A.M., Abdallah, M.A. and Döring, G. (1994) Iron Release from Transferrin by Pyoverdin and Elastase from Pseudomonas aeruginosa. Infection and Immunity, 62, 4021-4027. https://doi.org/10.1128/IAI.62.9.4021-4027.1994

76. Yanagihara, K., Tomono, K., Kaneko, Y., Miyazaki, Y., Tsukamoto, K., Hirakata, Y., Mukae, H., Kadota, J., Murata, I. and Kohno, S. (2003) Role of Elastase in a Mouse Model of Chronic Respiratory Pseudomonas aeruginosa Infection That Mimics Diffuse Panbronchiolitis. Journal of Medical Microbiology, 52, 531-535. https://doi.org/10.1099/jmm.0.05154-0

77. Kessler, E., Safrin, M., Olson, J.C. and Ohman, D.E. (1993) Secreted LasA of Pseudomonas aeruginosa Is a Staphylolytic Protease. Journal of Biological Chemistry, 268, 7503-7508.

78. Park, P.W., Pier, G.B., Preston, M.J., Goldberger, O., Fitzgerald, M.L. and Bernfield, M. (2000) Syndecan-1 Shedding Is Enhanced by LasA, a Secreted Virulence Factor of Pseudomonas aeruginosa. Journal of Biological Chemistry, 275, 3057-3064. https://doi.org/10.1074/jbc.275.5.3057

79. Daddaoua, A., Fillet, S., Fernández, M., Udaondo, Z., Krell, T. and Ramos, J.L. (2012) Genes for Carbon Metabolism and the ToxA Virulence Factor in Pseudomonas aeruginosa Are Regulated Through Molecular Interactions of PtxR and PtxS. PLoS ONE, 7, e39390. https://doi.org/10.1371/journal.pone.0039390

80. McEwan, D.L., Kirienko, N.V. and Ausubel, F.M. (2012) Host Translational Inhibition by Pseudomonas aeruginosa Exotoxin a Triggers an Immune Response in Caenorhabditis elegans. Cell \& Host Microbe, 11, 364-374.

https://doi.org/10.1016/j.chom.2012.02.007

81. Laarman, A.J., Bardoel, B.W., Ruyken, M., Fernie, J., Milder, F.J., van Strijp, J.A. and Rooijakkers, S.H. (2012) Pseudomonas aeruginosa Alkaline Protease Blocks Complement Activation via the Classical and Lectin Pathways. Journal of Immunology, 188, 386-393. https://doi.org/10.4049/jimmunol.1102162 
82. Lequette, Y. and Greenberg, E.P. (2005) Timing and Localization of Rhamnolipid Synthesis Gene Expression in Pseudomonas aeruginosa Biofilms. Journal of Bacteriology, 187, 37-44. https://doi.org/10.1128/JB.187.1.37-44.2005

83. Jensen, V., Löns, D., Zaoui, C., Bredenbruch, F., Meissner, A., Dieterich, Münch, R. and Häussler, S. (2006) RhlR Expression in Pseudomonas aeruginosa Is Modulated by the Pseudomonas Quinolone Signal via PhobDependent And-Independent Pathways. Journal of Bacteriology, 188, 8601-8606. https://doi.org/10.1128/JB.01378-06

84. Adam, E.C., Mitchell, B.S., Schumacher, D.U., Grant, G. and Schumacher, U. (1997) Pseudomonas aeruginosa II Lectin Stops Human Ciliary Beating: Therapeutic Implications of Fucose. American Journal of Respiratory and Critical Care Medicine, 155, 2102-2104. https://doi.org/10.1164/ajrccm.155.6.9196121

85. Ryall, B., Davies, J.C., Wilson, R., Shoemark, A. and Williams, H.D. (2008) Pseudomonas aeruginosa, Cyanide Accumulation and Lung Function in CF and Non-CF Bronchiectasis Patients. European Respiratory Journal, 32, 740-747. https://doi.org/10.1183/09031936.00159607

86. Jackowski, J.T., Szepfalusi, Z., Wanner, D.A., Seybold, Z., Sielczak, M.W., Lauredo, I.T., Adams, T., Abraham, W.M. and Wanner, A. (1991) Effects of $P$. aeruginosa-Derived Bacterial Products on Tracheal Ciliary Function: Role of $\mathrm{O}_{2}$ Radicals. American Journal of Physiology, 260, L61-L67. https://doi.org/10.1152/ajplung.1991.260.2.L61

87. Denning, G.M., Wollenweber, L.A., Railsback, M.A., Cox, C.D., Stoll, L.L. and Britigan, B.E. (1998) Pseudomonas Pyocyanin Increases Interleukin-8 Expression by Human Airway Epithelial Cells. Infection and Immunity, 66, 5777-5784. https://doi.org/10.1128/IAI.66.12.5777-5784.1998

88. Lau, G.W., Ran, H., Kong, F., Hassett, D.J. and Mavrodi, D. (2004) Pseudomonas aeruginosa Pyocyanin Is Critical for Lung Infection in Mice. Infection and Immunity, 72, 4275-4278.

https://doi.org/10.1128/IAI.72.7.4275-4278.2004

89. Diggle, S.P., Winzer, K., Chhabra, S.R., Worrall, K.E., Cámara, M. and Williams, P. (2003) The Pseudomonas aeruginosa Quinolone Signal Molecule Overcomes the Cell Density-Dependency of the Quorum Sensing Hierarchy, Regulates rhl-Dependent Genes at the Onset of Stationary Phase and Can Be Produced in the Absence of LasR. Molecular Microbiology, 50, 29-43. https://doi.org/10.1046/j.1365-2958.2003.03672.x

90. Wolska, K.I., Grudniak, A.M., Rudnicka, Z. and Markowska, K. (2016) Genetic Control of Bacterial Biofilms. Journal of Applied Genetics, 57, 225-238. https://doi.org/10.1007/s13353-015-0309-2

91. Joint, I., Tait, K., Callow, M.E., Callow, J.A., Milton, D., Williams, P. and Cámara, M. (2002) Cell-to-Cell Communication across the Prokaryote-Eukaryote Boundary. Science, 298, 1207.

https://doi.org/10.1126/science.1077075

92. Twigg, M.S., Tait, K., Williams, P., Atkinson, S. and Cámara, M. (2013) Interference with the Germination and Growth of Ulva Zoospores by Quorum-Sensing Molecules from Ulva-Associated Epiphytic Bacteria. Environmental Microbiology, 16, 445-453. https://doi.org/10.1111/1462-2920.12203

93. LaSarre, B. and Federle, M.J. (2013) Exploiting Quorum Sensing to Confuse Bacterial Pathogens. Microbiology and Molecular Biology Reviews, 77, 73-111. https://doi.org/10.1128/MMBR.00046-12

94. Defoirdt, T., Boon, N. and Bossier, P. (2010) Can Bacteria Evolve Resistance to Quorum Sensing Disruption? PLoS Pathogens, 6, e1000989. https://doi.org/10.1371/journal.ppat.1000989

95. Defoirdt, T., Brackman, G. and Coenye, T. (2013) Quorum Sensing Inhibitors: How Strong Is the Evidence? Trends in Microbiology, 21, 619-624. https://doi.org/10.1016/j.tim.2013.09.006

96. García-Contreras, R., Maeda, T. and Wood, T.K. (2013) Resistance to Quorum-Quenching Compounds. $A p$ plied and Environmental Microbiology, 79, 6840-6846. https://doi.org/10.1128/AEM.02378-13 
97. García-Contreras, R., Maeda, T. and Wood, T.K. (2016) Can Resistance against Quorum-Sensing Interference Be Selected? ISME Journal, 10, 4-10. https://doi.org/10.1038/ismej.2015.84

98. Zhang, L.H. and Dong, Y.H. (2004) Quorum Sensing and Signal Interference: Diverse Implications. Molecular Microbiology, 53, 1563-1571. https://doi.org/10.1111/j.1365-2958.2004.04234.x

99. Swem, L.R., Swem, D.L., Wingreen, N.S. and Bassler, B.L. (2008) Deducing Receptor Signaling Parameters from in Vivo Analysis: LuxN/AI-1 Quorum Sensing in Vibrio harveyi. Cell, 134, 461-473. https://doi.org/10.1016/j.cell.2008.06.023

100. Swem, L.R., Swem, D.L., O'Loughlin, C.T., Gatmaitan, R., Zhao, B., Ulrich, S.M. and Bassler, B.L. (2009) A Quorum-Sensing Antagonist Targets both Membrane-Bound and Cytoplasmic Receptors and Controls Bacterial Pathogenicity. Molecular Cell, 35, 143-153. https://doi.org/10.1016/j.molcel.2009.05.029

101. Heeb, S., Fletcher, M.P., Chhabra, S.R., Diggle, S.P., Williams, P. and Cámara, M. (2011) Quinolones: from Antibiotics to Autoinducers. FEMS Microbiology Reviews, 35, 247-274. https://doi.org/10.1111/j.1574-6976.2010.00247.x

102. Yan, S. and Wu, G. (2019) Can Biofilm Be Reversed through Quorum Sensing System in Pseudomonas aeruginosa? Frontiers in Microbiology, 10, 1582. https://doi.org/10.3389/fmicb.2019.01582 